\title{
Not All Fees Are Created Equal: Equity Implications OF RIDE-HAIL FEE STRUCTURES
}

\author{
PREPRINT \\ - Anne Brown \\ School of Planning, Public Policy, and Management \\ University of Oregon \\ 1209 University of Oregon \\ Eugene, OR 97402 \\ abrown330uoregon. edu
}

September 9, 2020

\begin{abstract}
Ride-hailing is a source of opportunity and consternation for cities, presenting both opportunities to expand mobility and added challenges such as increased congestion. In an effort to curb congestion - and to tap a new source of revenue - cities and states across the US have imposed fees on ride-hail trips. Fees are far from uniform; the fee bases, amounts levied, and use of these funds once collected range considerably between cities and states. Despite previous research that toll and transit fare structures affect equity, no research to date has examined the equity implications of ride-hail fee structures. This paper addresses that gap in understanding and asks: what are the equity implications of different ride-hail fee structures? I answer this question using trip-level data from over 97 million ride-hail trips taken in 2018 and 2019 in the City of Chicago. Examining trips serving low-, middle-, and high-income neighborhoods, I examine equity implications under four different fee scenarios: 1) flat rate, 2) percentage of fare, 3) varied rate for pooled trips, and 4) per mile fees. Fees that charge a percentage of total fare deliver a more progressive fee compared to flat, per-mile, or pool-differentiated fees. Yet stark income differences between neighborhoods means that even varied fees remain regressive with respect to income. Cities or states considering ride-hail fees should start by identifying concrete equity-first goals and design fee structures to achieve these goals. Cities should identify and require data needed to assess progress on identified goals and adjust fees as needed to better align with these goals. Far from being a silver bullet for issues like increasing congestion or bolstering transit funding, ride-hail fees should be seen as just one among a broader suite of policies needed to realize broader city goals.
\end{abstract}

Keywords ride-hail $\cdot$ equity $\cdot$ transportation network company $\cdot$ fee

\section{Introduction}

Since its introduction in 2012, ride-hailing has proven both a source of opportunity and consternation for cities. Transit agencies across the country have partnered with ride-hail companies to overcome first-last mile barriers (Federal Transit Administration, 2018), health care providers have subsidized ride-hail trips to help patients reach appointments (Esposito, 2018), and research finds that ride-hailing expands the geography of on-demand car access (Gehrke, 2020, Brown, 2019a). Yet cities also remain troubled by ride-hailing's negative externalities, including its added vehicle miles traveled (VMT) to congested city streets (San Francisco County Transportation Authority, 2018, Erhardt et al., 2019). In an effort to curb congestion - and to tap a new source of revenue - cities and states across the US have imposed fees on ride-hail trips. Fees are far from uniform; the fee bases, amounts levied, and use of these funds once collected range considerably between cities and states. Despite previous research that toll and transit fare structures affect equity (see for example Schweitzer and Taylor (2008); Farber et al. (2014)), no research to date has examined the equity 
implications of ride-hail fee structures. As more cities consider ride-hail fees and taxes, it is critical for cities to examine the equity implications of different fee structures.

To fill this gap in our understanding of ride-hail fee equity, I ask: what are the equity implications of different ride-hail fee structures? I answer this question using trip-level data from over 97 million ride-hail trips taken in 2018 and 2019 in the City of Chicago. Examining trips serving low-, middle-, and high-income neighborhoods, I examine equity implications of four different fee scenarios: 1) flat rate, 2) percentage of fare, 3) varied rate for pooled trips, and 4) per mile fees.

I divide the remainder of this paper into four sections. Following this introduction, I first review the existing ride-hail travel, ride-hail fee, and transportation fee and fare equity literature. Second, I overview the data and methods employed in this research. Third, I discuss results; and finally, I conclude with implications for transport policy.

\section{Literature Review}

Previous ride-hail research investigates traveler characteristics and trip-making (e.g. Conway et al. (2018)), the effects on congestion and added VMT (e.g. Henao and Marshall (2019)), and modal substitution (e.g. Grahn et al. (2020) and Dong (2020)). While some research to date has examined equity issues in ride-hailing, this research has focused primarily on user characteristics (Young and Farber, 2019, Conway et al., 2018), travel patterns and service characteristics across space (Hughes and MacKenzie, 2016, Brown, 2019a), and racial discrimination in ride-hailing (Ge et al., 2016, Moody et al., 2019, Brown, 2019b). While no research to date has assessed the potential equity implications of different ride-hail fee structures, previous ride-hail and transportation finance research offers insights into possible equity outcomes.

\subsection{Who uses Ride-hail?}

Research finds that ride-hail users are disproportionately higher-income (Clewlow and Mishra, 2017, Conway et al., 2018, Young and Farber, 2019, Dong, 2020), although users with low-incomes and living low-income neighborhoods use ride-hailing as much or more frequently than those with high-incomes and living in high-income neighborhoods (Gehrke et al., 2019, Conway et al., 2018, Brown, 2019a). Among ride-hail users, trip characteristics also diverge by income. Travelers living in low-income neighborhoods make shorter trips and are more likely to hail shared ride-hail trips compared to those living in middle- or higher-income neighborhoods (Brown, 2019a). Research finds a range of evidence about modal substitution in ride-hailing, and varyingly finds that ride-hailing complements and substitutes transit (Feigon and Murphy, 2018, Malalgoda and Lim, 2019, Babar and Burtch, 2020, Graehler et al., 2019, Clewlow and Mishra, 2017, Hall et al., 2018). Research also finds that some travelers substitute driving personal vehicles, and that ride-hailing generates trips that would not otherwise have been made (Lavieri and Bhat, 2019, Gehrke et al., 2019, Henao and Marshall, 2019). People use ride-hailing for a wide variety of trip purposes, but disproportionately for entertainment, recreational, and social purposes compared to other modes (Young and Farber, 2019, Lavieri and Bhat, 2019).

\subsection{Ride-hail Fees Across the US}

Ride-hail fees, while increasingly common, are not new; New York State first levied a 2.5\% fee on all ride-hail trips in 2011 - the year ride-hailing began - to finance the Black Car Fund, which provides workers' compensation insurance and health and safety programs to for-hire drivers (see Table 1). New York, however, was well ahead of other states and cities. Between 2011 and 2014, just three jurisdictions enacted ride-hailing fees (New York, California, and Seattle, WA). Since 2015, another 20 US cities and states have added fees ranging in structure and amount (see Figure 1). Table 1 shows that ride-hail fees fall into two primary categories: a flat per-trip fee that levies a set charge regardless of trip characteristics, and a variable fee calculated as a percentage of total fare 1 Even within these categories, fees range considerably. Chicago, which restructured its ride-hail fee in 2019, operates the most complex fee structure and charges different fees by time of day, if a trip is pooled (shared with another rider), or traveling to or from select surcharge zones. Chicago is also unique in that it expressly called out equity considerations in its 2019 fee restructuring (Spielman, 2019). Chicago's ride-hail fee, while unique in its combinations, includes many elements shared by other cities and states. Other cities and states also differentiate fees between solo and pooled trips (Georgia, New Jersey, New York City) or if

\footnotetext{
${ }^{1}$ California and New York both also charge percentage fees to ride-hail companies based on the total revenues collected in the state; these fees are based on gross revenues rather than levied on individual trips and are in addition to per-trip fees levied by the state.
} 
a trip begins within parish/city boundaries (New Orleans, Seattle). Flat fees range from $\$ 0.20$ per ride (Massachusetts) to $\$ 8.00$ per ride (Chicago, single-occupied trip in the downtown surcharge zone during peak hours). Like flat fees, percentage-based fees also vary by amount (from 1 percent in Alabama to 7\% in Rhode Island), trip origin location (e.g. Philadelphia levies $1.4 \%$ fee on trips originating inside the city), and based on pooling and vehicle emissions (e.g. San Francisco charges a $1.5 \%$ fee on pooled and zero-emission vehicle (ZEV) trips, but 3.25\% on solo non-ZEV trips).

Figure 1: States and cities charging ride-hail fees as of April 2020

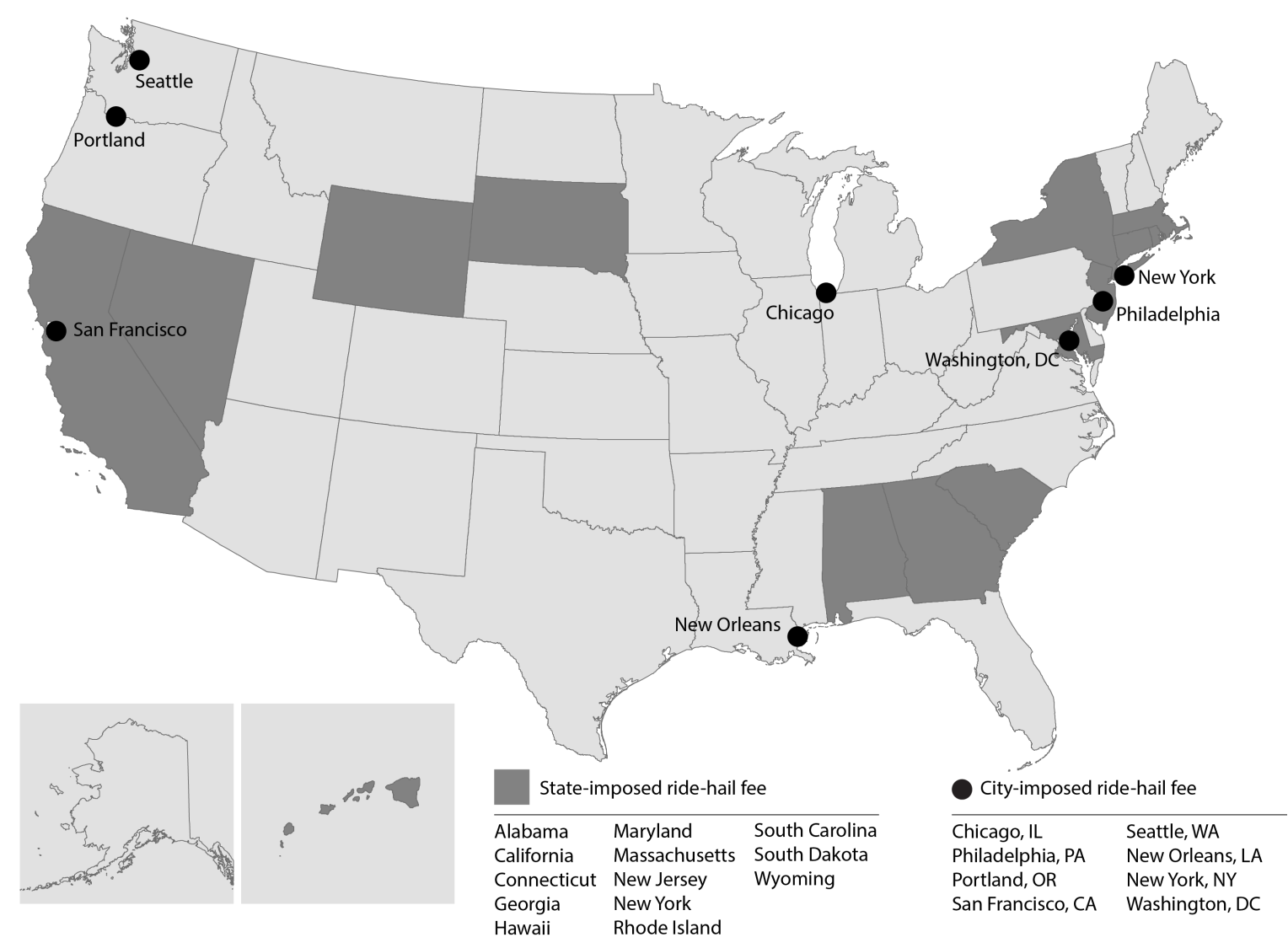

Ride-hail fees are under constant discussion in cities and states across the US. While Table 1 includes all enacted ride-hail fees, it does not include proposed fees that either were rejected by city leadership or remain under discussion. For example, in 2019, Oakland, CA dropped a proposal that would have charged $\$ 0.50$ per ride-hail trip (Bond Graham, 2019); Massachusetts is currently considering increasing its per-trip fee from $\$ 0.20$ to $\$ 1.00$ (Newcombe, 2020); and the Mayor of Boston (separate from any state-wide action) wants to levy a variable ride-hail fee based on vehicle emissions, time of day, and pooling (Enwemeka, 2019).

Ride-hail fees are motivated by a number of factors. Some argue that ride-hail fees are simply "an easy revenue target" to shore up general city budgets (Newcombe, 2020) or fund road maintenance. Other cities levy fees to combat the added VMT and congestion that ride-hailing adds to city roads; San Francisco, for example, named its ride-hail fee the "Traffic Congestion Mitigation Tax" in direct reference to the issue it's aiming to combat with the fee (San Francisco Treasurer, 2020). Others argue that fees should be designed to encourage vehicle fleet electrification (Slowik et al., 2019) or fund transit (e.g. New York City, San Francisco, Washington, D.C.). Corresponding to this array of motivations, ride-hail fees fund a variety of departments, programs, or funds across different cities and states (see Table 1). 
Table 1: Ride-hail Fees in the US as of April 2020

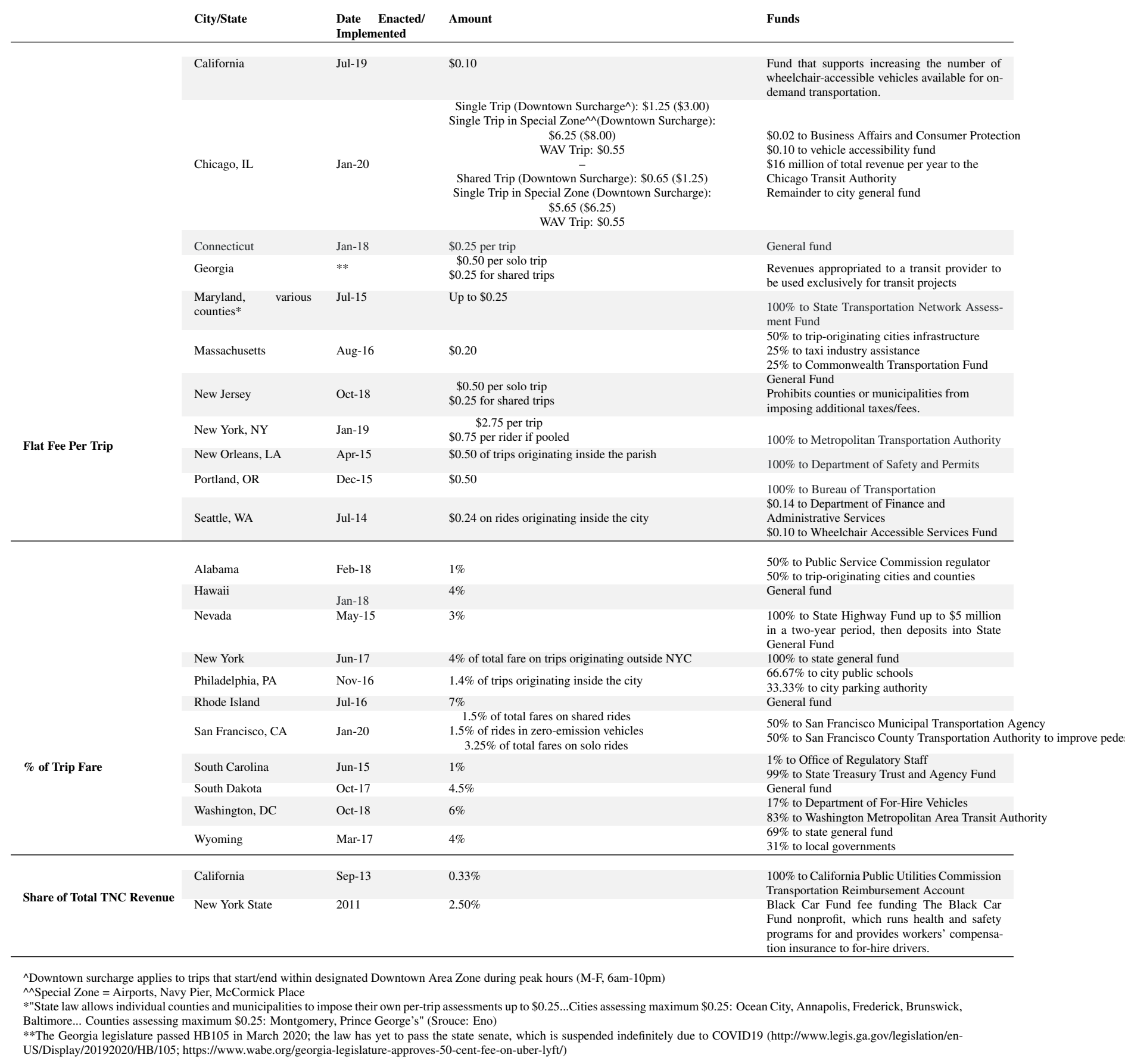

While cities espouse many different motivations for ride-hail fees, equity is rarely raised as a consideration in fee structure. Yet research on ride-hailing, transit fares, and transportation finance suggests that fee structures could have dramatic equity implications.

\subsection{Equity in Fares and Transportation Finance}

Previous research demonstrates that transit fare or transportation fee structure has important implications for equity. Research on transit fares repeatedly finds that fare structure has important implications. In particular, flat fares tend to be the most regressive with respect to income and distance-based fares more equitable, depending largely on urban 
Table 2: City of Chicago Ride-hail Trip Variables

\begin{tabular}{ll} 
Variable(s) & Description \\
\hline Geographic identifiers & $\begin{array}{l}\text { Census tract of trip origin and destination; latitude } \\
\text { and longitude of each census tract centroid } \\
\text { Date/time a trip started/ended to the nearest } 15 \\
\text { minutes }\end{array}$ \\
Timestamp & $\begin{array}{l}\text { In seconds } \\
\text { In miles }\end{array}$ \\
Trip duration & $\begin{array}{l}\text { Rounded to the nearest } \$ 2.50 \\
\text { Rounded to the nearest } \$ 1.00 ; \text { cash tips not in- } \\
\text { cluded } \\
\text { Fare }\end{array}$ \\
Tip & $\begin{array}{l}\text { Taxes, fees, other charges for trip; not rounded } \\
\text { In dollars; calculated as the sum of (rounded) fare, } \\
\text { (rounded) tip, and additional charges }\end{array}$ \\
Additional charge & $\begin{array}{l}\text { Yes/no; whether a rider agreed to share a trip with } \\
\text { another passenger, regardless of if they were actu- } \\
\text { ally matched with another rider }\end{array}$ \\
Total cost & $\begin{array}{l}\text { How many trips, including this one, were pooled } \\
\text { together }\end{array}$ \\
Pooled trip authorized & \\
\hline
\end{tabular}

geography such as the spatial distribution of transit-dependent populations (Farber et al., 2014, Nuworsoo et al., 2009, Brown, 2018). Dill et al. (1999) demonstrate that a wide range of transportation fees-including vehicle licensing, vehicle registration, and driver's license fees-are all regressive with respect to income; they also demonstrate that fee burden varies by household composition. Larsen et al. (2012) find that road user fee equity varies depending on how the fee is levied, such as if it is a flat fee or varies by location (urban vs. rural) or fuel efficiency. Schweitzer (2009) reviews multiple finance mechanisms, demonstrating that different fee structures within the same finance mechanism (e.g. tolls, emissions fees, registration fees, gas taxes) yield varied income-based equity outcomes.

\section{Data \& Methods}

This research applies four different fare scenarios, grounded in current practice from cities and states across the US, to over 97 million ride-hail trips in the City of Chicago. Using these data and scenarios, I compare how fees-measured as total amount, share of total fare, and per mile-vary across low, middle, and high-income neighborhoods and the implications for equity.

\subsection{Data}

To examine the equity implications of different ride-hail fee structures, I used trip-level ride-hail data from the City of Chicago. In November 2018, the City of Chicago began requiring ride-hail companies to report trip-level data; Table 2 lists the trip-level variables published by the City. The data include any trip taken partially or wholly within city limits.

Travelers hailed nearly 129 million ride-hail trips to/from/within the City of Chicago between November 2018 and December 2019. In this research, I used only those trips with at least one trip end (origin/destination) location. Trips may be missing origin/destination data if they began or ended at a location outside of city limits. In sum, 97,279,967 trips taken between November 2018 and December 2019 were associated with an origin census tract, destination tract, or both. Both trip fare and distance variables were cleaned to eliminate extreme outliers (top 0.1\%) from skewing calculated average values. For both trip distance and fares, I recoded values in the top $0.1 \%$ to be equal to the $99.9 \%$ value. Trip distances ranged from 0.5 to 546 miles; trips in the top $0.1 \%$ (over 51 miles) were recoded to equal 52 miles. Trip fares ranged from $\$ 2.50$ to $\$ 1,247$; trips in the top $0.1 \%$ (over $\$ 100$ ) were recoded to equal $\$ 100$. Recoding reduced the skewing effect these extreme outlying variables had in subsequent calculations, including average fares and trip distances by neighborhood.

To understand the socioeconomic context in which trips are taken, I used census tract-level data from the 2018 5-Year American Community Survey including median household income, car ownership, and racial/ethnic composition. 
Table 3: Ride-hail Fee Scenarios

\begin{tabular}{ll} 
Fee Scenario & Description \\
\hline Per-trip, flat & \$0.64 per trip \\
Per-trip, percentage & $4 \%$ of total fare (excluding tip, tolls, etc.) \\
Pooled differentiation & $\$ 0.50$ per solo trip \\
Per-mile & $\$ 0.25$ per pooled trip \\
\hline
\end{tabular}

\subsection{Methods}

For each of the 97.3 million trips, I calculated per-trip ride-hail fees under the four fare scenarios, listed in Table 3. The four scenarios are grounded in current practice and are the most common fee structures enacted by cities and states across the US to date (see Table 1). I apply the fee under each scenario to a trip's base fare, excluding tip or additional charges such as tolls. While straightforward calculations, similar methods have been employed repeatedly in transit research to calculate the equity implications of different transit fare structures (Farber et al., 2014, Nuworsoo et al., 2009, Hickey et al., 2010, Rao, 2018, Brown, 2018).

The first scenario is a flat per-trip fee regardless of trip characteristics such as distance or pooling; the flat rate is set at $\$ 0.64$ per trip, which is the average per-trip fee of those listed in Table 1 . The second scenario charges a percentage-based fee, calculated as 4 percent (the average of percentage fees listed in Table 1) of the base fare. The third scenario differentiates fees between solo and pooled trips. Solo trips are charged $\$ 0.50$ per trip and pooled trip $\$^{2}$ are charged $\$ 0.25$ per trip; these amounts mirror the most commonly imposed pooled fee structure, implemented in both New Jersey and Georgia (see Table 1). Other cities, also differentiate between pooled and solo rides, but charge higher rates; Chicago, for example, charges $\$ 1.25$ and $\$ 0.65$ and for solo and pooled trips, respectively. The fourth scenario adds an $\$ 0.11$ per mile fee to each trip; while no cities or states currently charge a per mile ride-hail fee, I include a per-mile structure given its prevalence in transit fare policy research (see for example Farber et al. (2014); Rao (2018); Brown, 2018). I calculated $\$ 0.11$ as the flat per-trip fee (\$0.64) divided by the average trip distance (6.00 miles).

After calculating fees for every trip under each of the four scenarios, I calculated mean fees per neighborhood (census tract) by averaging the fees for all trips taken to or from each neighborhood. I present results across three different neighborhood income groups representing the bottom income quartile $(<\$ 47,632)$, middle two income quartiles $(\$ 47,632-\$ 105,520)$, and top income quartiles $(>\$ 105,520)$; I refer to these quartile groups as low, middle, and high-income, respectively. Table 4 shows the neighborhood characteristics of the three neighborhood income groups. Compared to middle- and high-income neighborhoods, low-income neighborhoods are disproportionately zero car (32.3\% compared to $13.7 \%$ and $15.6 \%$, respectively) and non-white. More than three-quarters (77\%) of residents in low-income neighborhoods are non-white compared to $44.7 \%$ and $21.1 \%$ in middle- and high-income neighborhoods, respectively.

I compared total fee amounts, per-mile fee amounts, and fees' share of total fares across the three neighborhood income groups to assess income-based equity of the four different ride-hail fee scenarios. As discussed in the following section, data limitations preclude analysis of fee effects on individual users. Therefore, I assess equity by examining average fee expenditures across low-, middle-, and high-income neighborhoods under the different scenarios. Fees are deemed more equitable when the share of total fee, mean fee per mile, or mean fee amount is lower in low-income neighborhoods where residents earn less than in middle- or high-income neighborhoods. Fees are inequitable when trips originating or ending in low-income neighborhoods pay higher fees than trips serving middle- or high-income neighborhoods.

\subsection{Limitations}

This research has four primary limitations. First, findings quantify trips taken to/from different neighborhoods but do not necessarily reflect travel by residents who live in those neighborhoods. Ride-hail data do not include passenger identifying information or home location; therefore, it is not possible to differentiate between residents traveling home and, say, nightlife patrons going to a bar. As previous ride-hail surveys find that 70 percent of riders began or ended at home (Henao, 2017) —on par with the share of all trips that are home-based (NHTS, 2017)—it is safe to assume at least some of these trips are by local residents; however, these data preclude analysis of individual traveler incomes or travel

\footnotetext{
${ }^{2}$ As shown in Table 2, pooled trips include all trips where the passenger requested a pooled service; it does not guarantee that the trip was shared with another passenger.
} 
Table 4: Chicago Neighborhood Characteristics by Income

\begin{tabular}{lcccc} 
Neighborhood Mean & Low & Middle & High & Overall \\
\hline Median HH Income & $<\$ 47,632$ & $\$ 47,632-\$ 105,520$ & $>\$ 105,520$ & $\$ 82,929$ \\
$\%$ Zero Car HH & $32.30 \%$ & $13.70 \%$ & $15.60 \%$ & $20.50 \%$ \\
$\%$ White & $23.00 \%$ & $55.30 \%$ & $78.90 \%$ & $51.60 \%$ \\
$\%$ Black & $59.40 \%$ & $23.70 \%$ & $7.30 \%$ & $30.30 \%$ \\
$\%$ Asian & $2.86 \%$ & $7.20 \%$ & $8.70 \%$ & $6.40 \%$ \\
$\%$ Latinx & $29.60 \%$ & $29.816 \%$ & $8.70 \%$ & $24.20 \%$ \\
\% Other & $15.40 \%$ & $15.40 \%$ & $5.50 \%$ & $12.50 \%$ \\
Population Density $^{2}$ & 10 & 8.1 & 14.6 & 10.1 \\
Employment Density $^{3}$ & 3.5 & 4.2 & 18.9 & 7.6 \\
\hline
\end{tabular}

IIncludes those identifying as "Other" race, two or more races, Native Hawaiian/Pacific Islander, American Indian or Alaska Native. 2People per acre. 3Jobs per acre. Sources: 5-Year 2014-2018 American Community Survey; 2014 Smart Location Database.

behaviors. In the absence of rider data, I therefore discuss all trips in relation to the neighborhood that they serve and examine mean trip characteristics across low-, middle-, and high-income neighborhoods.

Second, data rounding create a margin of error for the percentage-based scenario. Trip fares are rounded to the nearest $\$ 2.50$, providing approximate rather than precise fee estimates under the percentage-based fee structure. All other fee scenarios, which are calculated by trip, trip pool authorization, and trip distance, allow for precise fee calculations.

Third, this research considers equity only in terms of the levied fees; it does not consider potential equity implications stemming from ride-hail fee expenditures (see Table 1). Previous research demonstrates that how fee or tax revenues are used can affect their overall equity. Eliasson and Mattsson (2006) find that using congestion toll revenues to support transit most benefits low-income groups, while using toll revenues to cut taxes would most benefit higher-income groups. The potential equity implications of ride-hail revenue spending remains beyond the scope of this paper and a topic for future research. The equity implications of fee revenues funneled to general funds, for example, may be impossible to discern as fees are lumped in with other city or state revenues and impossible to trace to specific outcomes or programs. Even when the revenue stream is clear, the net equity implications may remain murky, such as when ride-hail fee revenues are funneled into public schools.

Finally, this research—like previous research of transit fares (e.g. Farber et al. (2014); Rao (2018); Brown, 2018)—does not consider how added fees may or may not change travel behaviors. While some researchers have calculated initial estimates for price elasticity for ride-hail trip demand (Cohen et al., 2016), these estimates focus on responses to greater fare fluctuations such as surge pricing. Ride-hail fees often comprise a very small share of overall fares, making it possible that they alone do not sway traveler behavior. Previous research in economics finds that small fees like sales taxes hold little sway over consumer behaviors because either consumers may not be aware of the surcharge or the marginal price increases is not readily apparent at the time of purchase (Chetty et al., 2009, Finkelstein, 2007). Additionally, this research does not examine how elasticity varies by trip purpose, time of day, or rider characteristics. For example, research of Capital Bikeshare in Washington, D.C. finds that high-income users are less price sensitive than low-income users (Kaviti and Venigalla, 2018).

\section{Findings}

Analysis of over 97 million ride-hail trips reveals that trip fee structure has important implications for equity. Figure 2 shows the spatial distribution of neighborhood income, ride-hail trips, and ride-hail trips per capita across the City of Chicago. The maps show high-income neighborhoods centrally located around the downtown "Loop", concentrated to the north of downtown, and spatially sprinkled throughout neighborhoods more distant from downtown. Low-income neighborhoods are primarily located to the west and south of the Loop. More ride-hail trips are taken to/from and around downtown, even when accounting for the number of residents.

Table 5 shows varied trip characteristics across neighborhood income groups. Trips originating and ending in lowincome neighborhoods are shorter, more commonly pooled, and a higher proportion are during peak hours compared to middle- or high-income neighborhoods; these patterns conform to trip-level ride-hail research from Los Angeles 
Figure 2: Income, Trips, and Trips per Capita across Chicago Neighborhoods
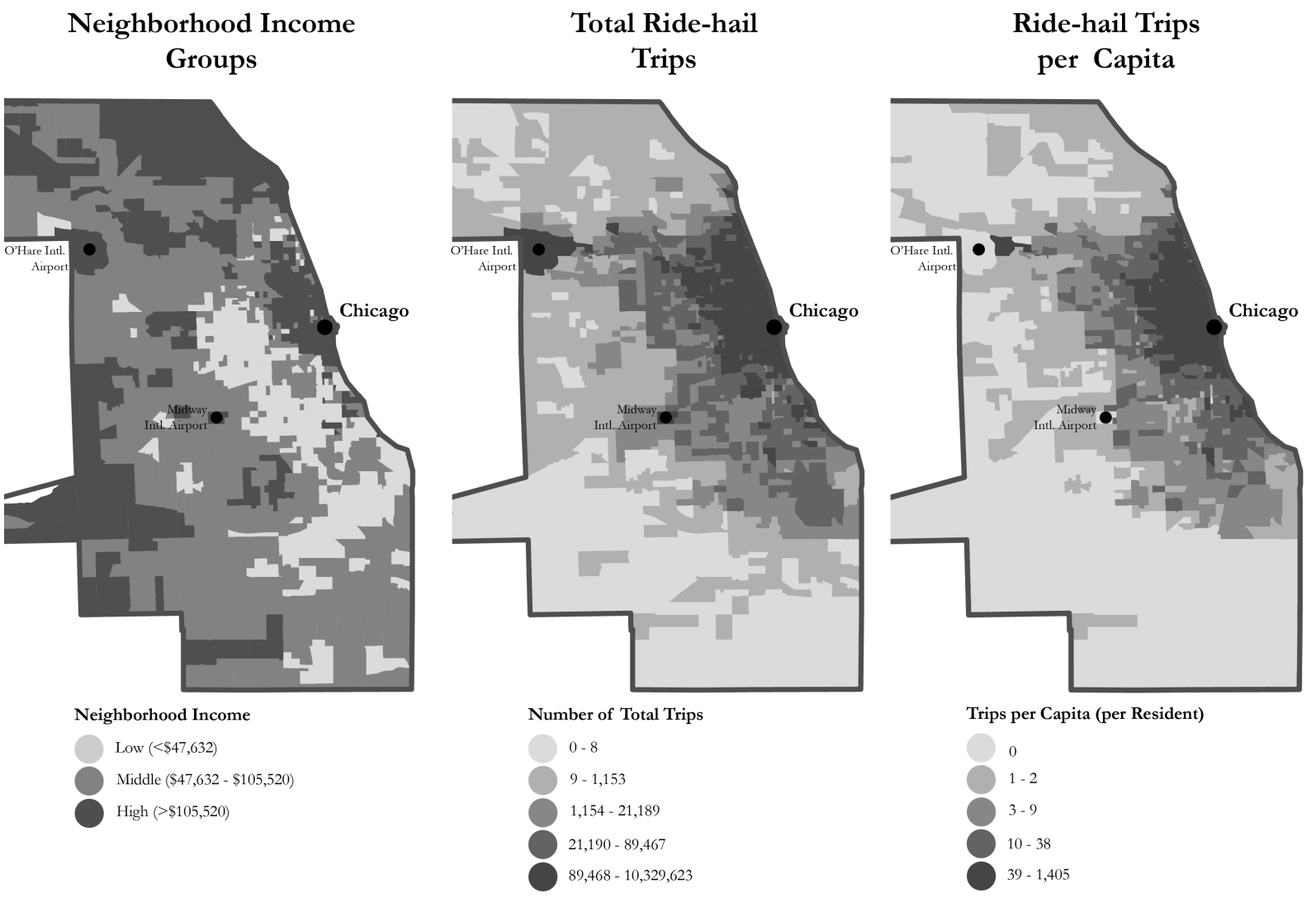

Table 5: Ride-hail Trip Characteristics by Neighborhood Income

\begin{tabular}{lllllllll}
\hline $\begin{array}{l}\text { Neighborhood } \\
\text { Income }\end{array}$ & Mean Fare & $\begin{array}{l}\text { Mean } \\
\text { Miles }\end{array}$ & Trip & $\begin{array}{l}\text { Mean \% Peak } \\
\text { Trips }\end{array}$ & $\begin{array}{l}\text { Mean \% Pool } \\
\text { Authorized }\end{array}$ & $\begin{array}{l}\text { Mean \% Actu- } \\
\text { ally Pooled }\end{array}$ & $\begin{array}{l}\text { Mean Trips } \\
\text { per Capita }\end{array}$ & $\begin{array}{l}\text { Share of Total } \\
\text { Ride-hail Trips }\end{array}$ \\
\hline Low & $\$ 11.95$ & 7.01 & $32.3 \%$ & $41.6 \%$ & $28.6 \%$ & 13.1 & $7 \%$ \\
Middle & $\$ 14.98$ & 9.10 & $30.1 \%$ & $31.0 \%$ & $19.0 \%$ & 16.6 & $16 \%$ \\
High & $\$ 15.43$ & 8.86 & $22.5 \%$ & $16.1 \%$ & $10.7 \%$ & 106.4 & $77 \%$ \\
Overall & $\$ 14.27$ & 8.47 & $28.7 \%$ & $29.9 \%$ & $19.4 \%$ & 39.2 & $100 \%$ \\
\hline
\end{tabular}

(Brown, 2019a). Contrasting to previous findings, which find more trips per capita taken in low-income neighborhoods (Brown, 2019a), nearly eight times as many trips per capita were taken in Chicago's high-income neighborhoods compared to low-income neighborhoods; this may be due in part to the greater population and employment densities in high-income relative to low-income neighborhoods (see Table 4).

Table 6 shows how varied trip characteristics translates into different average fee amounts paid across neighborhood income groups and fee structures. I discuss the equity implications of each of the four fee structures in turn.

Under a flat per-trip fee, trips serving low-income neighborhoods are subject to the highest per-mile fee $(\$ 0.20)$ and share of total fare $(7.90 \%)$, owing to shorter and cheaper trips serving these neighborhoods on average compared to middle- and higher-income neighborhoods. A flat fee structure also translates into higher fees per mile across all neighborhood income groups compared to any of the three other fare scenarios.

Fees levied as a percentage of trip fare are more equitable compared to flat fares. Because trips serving low-income neighborhoods have lower fares ( $\$ 11.95)$ compared to either middle- or high-income neighborhoods $(\$ 14.98$ and $\$ 15.43$, respectively), the levied fees are correspondingly lower. This translates to a progressive fee structure in terms of absolute dollars paid and nearly identical per-mile charges across the three neighborhood income groups. 
Table 6: Four Fee Scenario Results by Neighborhood Income

\begin{tabular}{|c|c|c|c|c|c|c|c|c|}
\hline \multirow[b]{2}{*}{ Neighborhood Income } & \multicolumn{2}{|c|}{ Per trip, flat fee $\mathbf{( \$ 0 . 6 4 )}$} & \multicolumn{2}{|c|}{ Per trip, percentage of fare $(4 \%)$} & \multicolumn{2}{|c|}{ Per trip, pool differentiation } & \multicolumn{2}{|c|}{ Per-mile (\$0.11/mile) } \\
\hline & $\begin{array}{l}\text { Mean } \\
\text { Share of } \\
\text { Total Fare }\end{array}$ & $\begin{array}{l}\text { Mean Fee } \\
\text { per Mile }\end{array}$ & $\begin{array}{l}\text { Mean Fee } \\
\text { Amount }\end{array}$ & $\begin{array}{l}\text { Mean Fee } \\
\text { Per Mile }\end{array}$ & $\begin{array}{l}\text { Mean } \\
\text { Share of } \\
\text { Total Fare }\end{array}$ & $\begin{array}{l}\text { Mean Fee } \\
\text { Per Mile }\end{array}$ & $\begin{array}{l}\text { Mean } \\
\text { Share of } \\
\text { Total Fare }\end{array}$ & $\begin{array}{l}\text { Mean Total } \\
\text { Fee Paid }\end{array}$ \\
\hline Low & $7.90 \%$ & $\$ 0.20$ & $\$ 0.48$ & $\$ 0.09$ & $4.71 \%$ & $\$ 0.12$ & $6.21 \%$ & $\$ 0.75$ \\
\hline Middle & $6.13 \%$ & $\$ 0.15$ & $\$ 0.60$ & $\$ 0.08$ & $3.92 \%$ & $\$ 0.10$ & $5.99 \%$ & $\$ 0.97$ \\
\hline High & $6.53 \%$ & $\$ 0.19$ & $\$ 0.62$ & $\$ 0.09$ & $4.57 \%$ & $\$ 0.13$ & $5.45 \%$ & $\$ 0.95$ \\
\hline Overall & $6.71 \%$ & $\$ 0.17$ & $\$ 0.57$ & $\$ 0.09$ & $4.30 \%$ & $\$ 0.12$ & $5.91 \%$ & $\$ 0.91$ \\
\hline
\end{tabular}

Pool-differentiated fees, charging $\$ 0.50$ per solo trip and $\$ 0.25$ per pooled trip, result in a bimodal distribution of fee payments, with trips in both low- and high-income neighborhoods paying higher shares of total fares and fees per mile compared to middle-income neighborhoods. Higher fees compared to middle-income neighborhoods, however, stem from two very different root causes. In low-income neighborhoods, despite nearly 42 percent of trip requests qualifying for discounted pooled fees $(\$ 0.25)$, shorter trip distances and lower fares still translate into fees that are higher per-mile and a greater share of the total fare. In high-income neighborhoods, most trips (84\%) are subject to the $\$ 0.50$ non-pooled fee. Yet because trips in high-income neighborhoods are also longer distance and more expensive on average, the solo fee price is more readily absorbed into the higher fares and constitutes lower shares of total and per-mile fares.

Trips serving low-income neighborhoods are 7 miles long on average compared to 8.9 and 9.0 miles in middle-and highincome neighborhoods, respectively. Different average trip distances across neighborhood income groups manifests in lower fees paid on trips serving low-income neighborhoods ( $\$ 0.75$ on average) and higher fees on trips serving middle- and high-income neighborhoods ( $\$ 0.97$ and $\$ 0.95$ on average, respectively). Yet as a share of total fare, trips serving low-income neighborhoods still pay more than trips serving either middle- or higher-income neighborhoods, due primarily to the far lower (23\%) fares for trips serving low-income neighborhoods; fares are positively correlated to distance $(0.849, \mathrm{p}<0.01)$ and negatively correlated to pool authorization $(-0.149, \mathrm{p}<0.01)$

\section{Discussion}

As this research shows, fee structures affect per-trip fees across low-, middle-, and high-income neighborhoods due to varied trip characteristics across space. Specifically, flat fees-like flat transit fares-are less equitable compared to fees that vary, and trips serving low-income neighborhoods pay both higher per-mile fees and higher shares of total fares in fees compared to trips serving middle- and high-income neighborhoods. Fees charging a percentage of the total fare prove the most equitable of the studied fee structures. While this research examines fee payments across neighborhoods rather than across individuals, ride-hail travel data suggest that neighborhood-wide travel trends observed here generally hold for individuals. Like average trips serving low-income neighborhoods, individual travelers living in low-income neighborhoods travel shorter distances, on lower-priced trips, and make a higher share of trips using pooled services (Brown, 2019a).

Varying ride-hail fees, however, is not a panacea for inequity. Under a per-mile fee structure, for example, trips serving low-income neighborhoods pay lower total fees, but those fees comprise a larger share of the total fare in lowincome $(6.2 \%)$ compared to high-income (5.5\%) neighborhoods, largely due to higher rates of pooling in low-income neighborhoods. Of the four fee scenarios examined in this research, the percentage-based fee was the most equitable. Under the percentage-based scenario, trips in low-income neighborhoods paid lower total fees and similar fees per mile compared to middle- and high-income neighborhoods. In even this "progressive" structure, however, the fees themselves may not be low enough to account for income disparities between low- and high-income neighborhoods. For example, under the percentage-based fee, the average trip in low-income neighborhoods would pay a $\$ 0.48$ fee compared to $\$ 0.62$ in a high-income neighborhood. While this average fee is $29 \%$ lower, the average household income is nearly $90 \%$ lower in low- compared to high-income Chicago neighborhoods. These discrepancies suggest that additional fee discounting would be needed to fully account for income differences across space $\mathrm{H}^{\beta}$

Ride-hail fees to date are evenly split between flat and percentage-based fees, and fee revenues fund a wide array of programs and agencies (see Table 1). Discussions of ride-hail fees often focus on these revenues, in part because of their

\footnotetext{
${ }^{3}$ US Census microdata show that the mean household income in the lowest quartile $(<\$ 47,632)$ is $\$ 22,422$; the mean household income in the highest quartile $(>\$ 105,520)$ is $\$ 209,302$. The lowest quartile average income is therefore $89.3 \%$ lower than the average income of the highest quartile (RUGGLES, S., FLOOD, S., GOEKEN, R., GROVER, J., MEYER, E., PACAS, J. \& SOBEK, M. 2020. IPUMS USA: Version 10.0 [dataset]. Minneapolis, MN.).
} 
potential to raise tremendous amounts of revenue. From November 2018 to December 2019, travelers hailed nearly 129 million trips in the City of Chicago. Under the four fee structures examined in this research, the City would have raised up to $\$ 82$ million over this 13 -month period. Yet using fees as simply a revenue generation tool is-as the former mayor of Portland, OR put it—a "lazy ride-hailing tax" (Adams, 2018). Ride-hail fees hold potential beyond generating revenue; they can help advance a cadre of city goals, including more equitable transportation. Before levying fees, cities should consider their goals. If, for example, the purpose of the fee is to mitigate congestion (as purported by some cities), cities may consider discounting pooled ride fees to encourage higher vehicle occupancy. If the goal is to reduce emissions, cities could impose a total mileage fee levied on the company (rather than on the driver), including deadhead miles when no passenger is in the vehicle to encourage more efficient routing and pooling; the equity implications of company-wide fees remain an area for future research. No matter the concurrent goals, equity should be a primary aim for all fees. A discounted pooled fee can discourage solo trips (and in doing so, help climate and congestion), but it would also translate into lower fees in low-income neighborhoods. Fees could also be employed to combat transportation exclusion or support transit access; cities could, for example, waive fees for rides that started or ended at a transit station or served transit deserts where residents face mobility constraints and where research finds that shared mobility services are lacking (Jiao and Wang, 2020).

Using fees to achieve specific city or state goals cannot be done without robust trip-level data to monitor fee compliance. Proactive decision-making about the data needed to assess fee compliance, track city goals, and examine pre-defined metrics will help streamline data sharing conversations, data storage, maintenance, and analysis. Data sharing agreements between cities and ride-hail companies should be tailored to meet city needs to evaluate if the fee structure is delivering on espoused goals or must be adjusted to better align to those goals. Although researchers and cities often default to "more data are better", strategic data reporting requirements may be preferable to broad data asks for two reasons. First, requesting all data associated with ride-hail trips may entangle cities in prolonged negotiations with ride-hail companies as companies regard data as trade secrets and are reticent to share even some, let alone all, data. And second, cities may not have the capacity — or need - for all data associated with every trip. This project is a perfect example of how data could overwhelm city capacity: the trip data used in this project-which included 13 months of trip-level data and a relatively parsimonious list of variables for each trip-were downloaded as a 34 GB file with nearly 129 million records, a file too large for standard desktop computer to open let alone analyze. Interactive data dashboards or partnerships with organizations like universities with supercomputing resources may help cities analyze ride-hail travel.

Cities have many different goals for ride-hail fees including mitigating congestion and supporting transit (see Table 1). But ride-hail fees will not achieve any of these goals absent complementary policies. Levying blanket fees on ride-hailing alone, for example, is unlikely to make a dramatic difference in congestion. While research finds that ridehailing contributes to both VMT and hours of delay (see for example San Francisco County Transportation Authority (2018)), it also finds that congestion would still be rising absent ride-hailing, and ride-hailing comprises a small fraction of total VMT added each year to city roads (Erhardt et al., 2019, San Francisco County Transportation Authority, 2018). Additionally, previous finds that small fees yield little effect on consumer behaviors because consumers may not be aware of the surcharge and/or the marginal price hike is not clear at the time of purchase (Chetty et al., 2009, Finkelstein, 2007). If cities are to tackle their broader goals—-such as mitigating congestion, supporting transit, and improving equitable mobility - ride-hailing fees can certainly be part of the equation, but they are far from a silver bullet. More comprehensive policies that address both hailed rides and personally-owned cars (such as widespread congestion pricing) would likely yield more tangible effects. Comprehensive policies that consider personal car travel in addition to ride-hailing would also likely prove more equitable given frequent ride-hail use among low-income travelers and those living in low-income neighborhoods (Conway et al., 2018, Brown, 2019a). In other words, ride-hail fees absent widespread road pricing may disproportionately fall on non-car owners who purchase car access one trip at a time, rather than higher-income car owners who comprise the bulk of road users.

Finally, future research should consider how equity is shaped not only by the fee structure, but also by what fees fund. Previous transportation finance research suggests that how revenues are used can shift the balance of equity for a fee or tax (Eliasson and Mattsson, 2006). Future research may consider how using revenues to support different agencies or programs could affect the redistribution of dollars between traveler groups.

\section{Conclusion}

Ride-hail fee structures yield important implications for equity. Fee structures that impose a percentage-based fee deliver a more progressive fee structure compared to flat, per-mile, or even pool-differentiated fees. Yet stark income differences between neighborhoods likely means variable fees may still be regressive. Ride-hail fees present a tempting 
source of new revenue, but hold potential beyond generating funds. Fees are one tool among a suite of policies that can be leveraged to advanced city goals, including more equitable transportation. Cities or states considering ride-hail fees should design fee structures in line with broader transportation policy objectives, and consider equity at the forefront of all discussions. Cities should identify and require data needed to assess progress on identified goals and adjust fees as needed to better align with these goals. Far from being a silver bullet for issues like increasing congestion or bolstering transit funding, ride-hail fees should be seen as just one among a broader suite of policies needed to realize broader city goals, and one that requires concerted efforts to address potential equity concerns.

\section{References}

ADAMS, S. 2018. Don't Enact a 'Lazy' Ride-Hailing Taz. CityLab.

BABAR, Y. \& BURTCH, G. 2020. Examining the Heterogeneous Impact of Ride-Hailing Services on Public Transit Use. Information Systems Research.

BOND GRAHAM, D. 2019. Lyft donates $\$ 700,000$ to Oakland after quietly battling city taxes. The Guardian.

BRINKLOW, A. 2019. Ride-hailing tax squeaking through. Curbed San Francisco [Online]. Available from: https://sf.curbed.com/2019/11/6/20951181/san-francisco-sf-election-lyft-uber-fee-tax.

BROWN, A. 2019a. Redefining car access: ride-hail travel and use in Los Angeles. Journal of the American Planning Association, 85(2), 83-95.

BROWN, A. E. 2019. Prevalence and mechanisms of discrimination: Evidence from the ride-hail and taxi industries. Journal of Planning Education and Research.

BROWN, A. E. 2018. Fair fares? How flat and variable fares affect transit equity in Los Angeles. Case Studies on Transport Policy, 6(4), 765-773.

CALIFORNIA PUBLIC UTILITIES COMMISSION 2018. TNC: Accessibility for Persons with Disabilities Program (SB 1376, Hill).

CHETTY, R., LOONEY, A. \& KROFT, K. 2009. Salience and taxation: Theory and evidence. The American economic review, 99, 1145-1177.

CITY OF CHICAGO. 2020a. City of Chicago Congestion Pricing.

CITY OF CHICAGO 2020b. Municipal code 3-46 Ground Transportation Tax.

CITY OF SEATTLE 2020. Business Regulations: Transportation Network Companies.

CLEWLOW, R. R. \& MISHRA, G. S. 2017. Disruptive Transportation: The Adoption, Utilization, and Impacts of Ride-Hailing in the United States. UC Davis Institute of Transportation Studies.

COHEN, P., HAHN, R., HALL, J., LEVITT, S. \& METCALFE, R. 2016. Using big data to estimate consumer surplus: The case of uber. National Bureau of Economic Research.

CONNECTICUT GENERAL ASSEMBLY 2020. § 654 - TRANSPORTATION NETWORK COMPANY (TNC) FEE.

CONWAY, M., SALON, D. \& KING, D. 2018. Trends in Taxi Use and the Advent of Ridehailing, 1995-2017: Evidence from the US National Household Travel Survey. Urban Science, 2, 79.

DILL, J., GOLDMAN, T. M. \& WACHS, M. 1999. California vehicle license fees: incidence and equity. Journal of Transportation and Statistics, 2, 133-148.

DONG, X. 2020. Trade Uber for the Bus? An Investigation of Individual Willingness to Use Ride-Hail Versus Transit. Journal of the American Planning Association, 86, 222-235.

ELIASSON, J. \& MATTSSON, L.-G. 2006. Equity effects of congestion pricing: quantitative methodology and a case study for Stockholm. Transportation Research Part A: Policy and Practice, 40, 602-620.

ENWEMEKA, Z. 2019. Mayor Walsh Wants To Increase Fees On Uber And Lyft Rides. WBUR.

ERHARDT, G. D., ROY, S., COOPER, D., SANA, B., CHEN, M. \& CASTIGLIONE, J. 2019. Do transportation network companies decrease or increase congestion? Science advances, 5, eaau2670.

ESPOSITO, L. 2018. Lyft and Uber Help Patients Make It to Medical Appointments. US News and World Report. 
FARBER, S., BARTHOLOMEW, K., LI, X., PÁEZ, A. \& HABIB, K. M. N. 2014. Assessing social equity in distance based transit fares using a model of travel behavior. Transportation Research Part A: Policy and Practice, 67, 291-303.

FEDERAL TRANSIT ADMINISTRATION. 2018. Mobility on Demand (MOD) Sandbox Program [Online]. Available: https://www.transit.dot.gov/research-innovation/mobility-demand-mod-sandbox-program.html [Accessed].

FEIGON, S. \& MURPHY, C. 2018. Broadening Understanding of the Interplay Between Public Transit, Shared Mobility, and Personal Automobiles. Transportation Cooperative Research Program. Washington, D.C.: Transportation Research Board.

FINKELSTEIN, A. 2007. E-ztax: Tax salience and tax rates. National Bureau of Economic Research.

GE, Y., KNITTEL, C. R., MACKENZIE, D. \& ZOEPF, S. 2016. Racial and Gender Discrimination in Transportation Network Companies. National Bureau of Economic Research.

GEHRKE, S. R. 2020. Uber service area expansion in three major American cities. Journal of Transport Geography, 86, 102752.

GEHRKE, S. R., FELIX, A. \& REARDON, T. G. 2019. Substitution of ride-hailing services for more sustainable travel options in the greater Boston region. Transportation Research Record, 2673, 438-446.

GEORGIA GENERAL ASSEMBLY. 2019-2020. Income tax; certain income received by taxpayers as payments from a disaster relief or assistance program administered by the United States Department of Agriculture in connection with Hurricane Michael; exempt. 2019-2020 Regular Session ed.

GEORGIA LEGISLATURE 2020. Title 48 of the Official Code of Georgia Annotated.

GRAEHLER, M., MUCCI, R. A. \& ERHARDT, G. D. Understanding the recent transit ridership decline in major US cities: service cuts or emerging modes. 98th Annual Meeting of the Transportation Research Board (TRB), Washington DC, 2019.

GRAHN, R., QIAN, S., MATTHEWS, H. S. \& HENDRICKSON, C. 2020. Are travelers substituting between transportation network companies (TNC) and public buses? A case study in Pittsburgh. Transportation, 1-29.

HALL, J. D., PALSSON, C. \& PRICE, J. 2018. Is Uber a substitute or complement for public transit?

HENAO, A. 2017. Impacts of Ridesource - Lyft and Uber - on Transportation including VMT, Mode Replacement, Parking, and Travel Behavior. Doctoral Dissertation. Denver: University of Colorado, Denver.

HENAO, A. \& MARSHALL, W. E. 2019. The impact of ride-hailing on vehicle miles traveled. Transportation, 46, 2173-2194.

HICKEY, R., LU, A. \& REDDY, A. 2010. Using quantitative methods in equity and demographic analysis to inform transit fare restructuring decisions. Transportation Research Record: Journal of the Transportation Research Board, 80-92.

HUGHES, R. \& MACKENZIE, D. 2016. Transportation network company wait times in Greater Seattle, and relationship to socioeconomic indicators. Journal of Transport Geography, 56, 36-44.

HURT, E. 2020. Georgia Legislature Approves 50 Cent Fee on Uber, Lyft. WABE.

JIAO, J. \& WANG, F. 2020. Shared mobility and transit-dependent population: A new equity opportunity or issue? International Journal of Sustainable Transportation, 1-12.

KAVITI, S. \& VENIGALLA, M. Modeling bikeshare user sensitivity and elasticity to pricing using monadic design and ordered logit. Submitted for Presentation at the 98th Annual Meeting (Jan 13-17, 2019) in Washington DC. National Research Council.(In review), 2018.

KIM, S. J. \& PUENTES, R. 2018. Taxing New Mobility Services: What's Right? What's Next? : Eno Center for Transportation.

LARSEN, L., BURRIS, M., PEARSON, D. \& ELLIS, P. 2012. Equity evaluation of fees for vehicle miles traveled in Texas. Transportation research record, 2297, 11-20.

LAVIERI, P. S. \& BHAT, C. R. 2019. Investigating objective and subjective factors influencing the adoption, frequency, and characteristics of ride-hailing trips. Transportation Research Part C: Emerging Technologies, 105, 100-125.

MALALGODA, N. \& LIM, S. H. 2019. Do transportation network companies reduce public transit use in the US? Transportation Research Part A: Policy and Practice, 130, 351-372. 
MOODY, J., MIDDLETON, S. \& ZHAO, J. 2019. Rider-to-rider discriminatory attitudes and ridesharing behavior. Transportation Research Part F: Traffic Psychology and Behaviour, 62, 258-273.

NEW JERSEY TREASURY 2018. Notice Transportation Network Company Prearranged Ride Surcharge (P.L. 2018, c. 47).

NEWCOMBE, T. 2020. Massachusetts Bets Big by Raising Ride-Sharing Surcharges. Governing [Online]. Available from: https://www.governing.com/finance/Massachusetts-Bets-Big-by-Raising-Ride-Sharing-Surcharges.html.

NHTS 2017. 2017 National Household Travel Survey. In: FHA, U. S. D. O. T. (ed.).

NUWORSOO, C., GOLUB, A. \& DEAKIN, E. 2009. Analyzing equity impacts of transit fare changes: Case study of Alameda-Contra Costa Transit, California. Evaluation and program planning, 32, 360-368.

RAO, P. 2018. Transit fare structure and equity: Case of MARTA, Atlanta.

RUGGLES, S., FLOOD, S., GOEKEN, R., GROVER, J., MEYER, E., PACAS, J. \& SOBEK, M. 2020. IPUMS USA: Version 10.0 [dataset]. Minneapolis, MN.

SAN FRANCISCO COUNTY TRANSPORTATION AUTHORITY 2018. TNCs and Congestion.

SAN FRANCISCO TREASURER. 2020. Traffic Congestion Mitigation Tax (TCM) [Online]. Available:

SCHWEITZER, L. 2009. The empirical research on the social equity of gas taxes, emissions fees, and congestion charges. Transportation Research Board Special Report. Washington, D.C.: Transportation Research Board.

SCHWEITZER, L. \& TAYLOR, B. D. 2008. Just pricing: the distributional effects of congestion pricing and sales taxes. Transportation, 35, 797-812.

SLOWIK, P., WAPPELHORST, S. \& LUTSEY, N. 2019. How can taxes and fees on ride-hailing fleets steer them to electrify? : The International Council on Clean Transportation.

SPIELMAN, F. 2019. Lightfoot exploring higher ride-hailing fees on solo riders in congested areas. Chicago Sun Times.

YOUNG, M. \& FARBER, S. 2019. The who, why, and when of Uber and other ride-hailing trips: An examination of a large sample household travel survey. Transportation Research Part A: Policy and Practice, 119, 383-392. 